\title{
Efficacy and Safety of Foley Catheter Balloon for Cervix Priming in Term Pregnancy
}

\section{Eficácia e Segurança do Cateter de Foley para Maturação Cervical Pré-Indução na Gravidez de Termo}

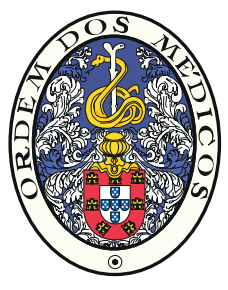

\author{
Catarina POLICIANO ${ }^{1}$, Mariana PIMENTA ${ }^{1}$, Diana MARTINS², Nuno CLODE
}

Acta Med Port 2017 Apr;30(4):281-284 - https://doi.org/10.20344/amp.8003

\section{ABSTRACT}

Introduction: Foley catheter promotes cervix priming by a direct mechanical effect of distension.

Material and Methods: A prospective observational study was conducted at a tertiary hospital, including all cases of induction of labor with Foley catheter between September 1, 2013 and November 30, 2015. Women were eligible if they had a singleton pregnancy with a Bishop score $<6$ and a gestational age $\geq 41$ weeks or a medical indication for induction of labor. The primary outcome was the Bishop score variation (difference between Bishop score before and after insertion of Foley catheter). Mode of delivery, induction-to-delivery time, uterine tachysystole with fetal decelerations, peripartum fever $\geq 38^{\circ} \mathrm{C}$, maternal pain and mortality were also analyzed.

Results: Within 201 inductions with Foley catheter, average increase in Bishop score after catheter placement was three (1 - 7), with only $5 \%(11 / 201)$ of unmodified cervix after catheter removal/extrusion. Vaginal delivery rate was $71 \%(142 / 201)$ and in women with a previous cesarean section $(n=40)$ was $37 \%(15 / 40)$. Average induction-to-delivery time was 38 hours $(4-120)$. Uterine infection rate was $3 \%(6 / 201)$. There was only one case of significant vaginal bleeding which required immediate catheter removal. There has been no significative maternal or neonatal morbidity.

Discussion/Conclusion: Foley catheter is a safe and effective method of cervical priming for women with an unfavorable cervix, even in the case of a previous cesarean delivery.

Keywords: Catheterization/methods; Cervical Ripening; Labor, Induced

\section{RESUMO}

Introdução: O cateter de Foley promove maturação cervical devido ao efeito mecânico directo de distensão.

Material e Métodos: Estudo prospectivo observacional realizado num hospital terciário, incluindo todas as induções do trabalho de parto com cateter de Foley entre 01 de setembro de 2013 e 30 de novembro de 2015. Incluíram-se grávidas de feto único, com um índice de Bishop < 6 e idade gestacional $\geq 41$ semanas, ou indicação médica para indução. O desfecho primário foi a variação do índice de Bishop (diferença entre índice de Bishop antes e após inserção do cateter de Foley). Os desfechos secundários foram: tipo de parto, intervalo de tempo indução-parto, taquissistolia com desacelerações da frequência cardíaca fetal, febre periparto $\geq 38^{\circ} \mathrm{C}$ dor materna e mortalidade.

Resultados: Incluíram-se 201 induções do trabalho de parto com cateter de Foley. Verificou-se um aumento médio do índice de Bishop após a colocação do cateter de três (1 - 7), com apenas $5 \%$ dos casos (11/201) sem qualquer modificação do colo após a remoçãol extrusão do cateter. A taxa de parto vaginal foi 71\% (142/201) e nas grávidas com uma cesariana anterior $(n=40)$ foi 37\% (15/40). A média do intervalo de tempo indução-parto foi 38 horas (4 - 120). A taxa de infecção uterina foi 3\% (6/201). Um caso de hemorragia vaginal significativa exigiu a remoção do cateter. Não se registou morbilidade materna ou neonatal significativa.

Discussão/Conclusão: O cateter de Foley é um método seguro e eficaz para maturação cervical em grávidas com colo desfavorável, mesmo com cesariana anterior.

Palavras-chave: Cateterização/métodos; Maturidade Cervical; Trabalho de Parto Induzido

\section{INTRODUCTION}

Induction of labor in women with an unfavorable cervix is a challenge for every particular pregnant woman since what is desired - a short labor with a high rate of vaginal delivery - is not easily reached. In fact, in case of unfavorable cervix, usually defined as a Bishop score less than 6 , the efficacy of labor induction is lower compared to a favorable cervix. Thus, in the former group, cervical priming is usually required before induction. ${ }^{1}$

Mechanical methods, including the use of cervical catheters or cervical dilators, contribute to the modification of physical and chemical properties of the cervix by a direct mechanical effect of distension and secondarily by promoting the release of prostaglandins. Cervix priming with mechanical methods for term pregnancy with unfavorable cervix has been demonstrated to be as effective as priming with prostaglandins but associated with less adverse effects. ${ }^{2,3}$ Compared to pharmacological agents, mechanical methods have fewer systemic effects and are associated with lower rates of tachysystole; they have a lower cost and do not require specific conditions of storage and refrigeration. ${ }^{4}$ However, the introduction of mechanical methods may contribute to maternal discomfort and have been associated with a potential risk of maternal and neonatal infection. ${ }^{5}$

The aim of the present study was to analyze the efficacy and safety of cervix priming with Foley catheter.

1. Department of Obstetrics and Gynecology. Hospital Universitário de Santa Maria. Academic Medical Center of Lisbon. Lisbon. Portugal.

2. Department of Obstetrics and Gynecology. Hospital Beatriz Ângelo. Loures. Portugal.

$\triangle$ Autor correspondente: Catarina Policiano. catarinapoliciano@gmail.com

Recebido: 01 de julho de 2016 - Aceite: 10 de novembro de 2016 | Copyright @ Ordem dos Médicos 2017 


\section{MATERIAL AND METHODS}

This is a prospective observational study that included all cases of induction of labor with Foley catheter in a tertiary hospital and took place between September 1, 2013 and November 30, 2015. The study was approved by the local Ethics Committee.

The present study included all women with a single fetus in cephalic presentation, Bishop score $(B S)<6$, gestational age $\geq 41$ weeks or medical indication for induction of labor that were submitted to cervix priming with Foley catheter. Women with a fetus in noncephalic presentation, an indication for elective cesarean delivery, spontaneous labor, hydramnios (amniotic fluid index $\geq$ 25), nonreassuring cardiotocogram, a multiple pregnancy, rupture of membranes, active vaginal bleeding, indication for prophylaxis of Streptococcus group B infection, HIV infection, cervical injury or previous cesarean section with recurrent indication were excluded.

The protocol of our Department for the induction of labor with mechanical methods implies the use of a single balloon (Foley catheter nr. 16F). The introduction of a deflated catheter through the outer cervix orifice is preceded by iodine disinfection of the cervix. The catheter is introduced under direct visualization and passed through the cervix in order to place the balloon above the internal os and then it is distended with $40 \mathrm{~mL}$ of a saline solution. The external end of the device is taped with tension to the medial aspect of the woman's thigh. Manual traction is applied to the catheter every six hours and if it is not spontaneously extruded it is removed 24 hours later. Before or during cervical priming with Foley catheter no antibiotic prophylaxis is performed. Independently of spontaneous extrusion of the catheter or manual removal, the induction of labor is carried out in accordance with BS and, for that purpose, we use prostaglandins if $\mathrm{BS}<6$ or oxytocin if $\mathrm{BS} \geq$ 6. Our standard regimen for labor induction is misoprostol, vaginal administration of $25 \mathrm{mcg}$ every 4 hours for a total of 24 hours. In case of BS $<6$ after 24 hours of misoprostol, the woman rests for 24 hours and then restarts a new cycle of a maximum of five misoprostol administrations. Prostaglandins are not used in the case of a previous uterine scar.

The primary outcome measure was variation of BS (difference between BS before and after application of FC) during cervix priming with Foley catheter. Secondary outcomes were mode of delivery, induction-to-delivery time, tachysystole with fetal decelerations, intrapartum and postpartum fever $\geq 38^{\circ} \mathrm{C}$, maternal pain, maternal and neonatal morbidity and mortality.

Nonreassuring fetal status was diagnosed based on cardiotocography, using the American College of Obstetricians and Gynecologists (ACOG) classification. ${ }^{6}$

In accordance with the United States National Institute of Child Health and Human Development, Society of Maternal-Fetal Medicine, and American College of Obstetricians and Gynecologists, we considered failed induction as failure to generate regular contractions approximately every three minutes and cervical change after at least 24 hours of Oxytocin administration. Membranes should be artificially ruptured, if safe and feasible. After rupture of membranes, the induction may be considered a failure if regular contractions and cervical change do not occur after at least 12 hours of oxytocin administration. ${ }^{7}$ In case of BS $<6$ after Foley catheter removal or extrusion, failed induction was considered when BS $<6$ persisted after 10 misoprostol administrations according to our protocol. In patients with a previous cesarean section, a BS $<6$ after Foley catheter removal or extrusion was considered a failed induction; if $B S \geq 6$ induction proceeded with oxytocin.

Maternal pain associated with the introduction of the Foley catheter was determined with the visual analog scale for pain (VAS Pain 0 - 10). The patient was asked to quantify the pain before the introduction of the catheter and again after its removal or extrusion. Patients in the second evaluation were asked to report the maximum pain during the cervix priming with Foley catheter. The maximum pain score was considered clinically relevant when it was at least moderate $(\geq 3)$.

Data processing was carried out using SPSS version 21.0 (IBM, Amonk, NY, USA). Statistical analysis was performed using the Mann-Whitney $U$ and $\chi 2$ tests. $p<0.05$ was considered statistically significant.

\section{RESULTS}

We included 201 patients submitted to induction of labor with Foley catheter. Demographic characteristics are represented in Table 1. The main indications for labor induction were gestational age above 41 weeks (72/201) and hypertensive disorders of pregnancy (44/201).

\section{Table 1 - Demographic characteristics}

\begin{tabular}{ll}
\hline Characteristics & $\mathbf{n}(\%)$ \\
\hline $\begin{array}{l}\text { Maternal age }(\mathrm{y}) \\
(\text { mean } \pm \mathrm{SD})\end{array}$ & $31.2 \pm 6.2$ \\
$\mathrm{BMI}\left(\mathrm{kg} / \mathrm{m}^{2}\right)$ & \\
$(\mathrm{mean} \pm \mathrm{SD})$ & $26.7 \pm 5.4$ \\
Race & \\
Caucasian & $172(86)$ \\
Black & $29(14)$ \\
Parity & \\
Nulliparous & $139(69)$ \\
Multiparous & $62(31)$ \\
Gestational age at delivery (wk) \\
(mean \pm SD) \\
Indication for induction of labor & $38.7 \pm 2.0$ \\
Gestational age $>41$ weeks & \\
Hypertension & \\
Fetal growth restriction & $72(36)$ \\
Cholestasis & $44(22)$ \\
Diabetes & $31(15)$ \\
Others & $27(13)$ \\
\hline But Body mass index & $14(6)$ \\
& $13(6)$ \\
\hline
\end{tabular}

BMI: Body mass index 
Table 2 - Obstetric outcomes

\begin{tabular}{ll}
\hline Obstetric outcomes & $\mathbf{n}(\%)$ \\
\hline $\begin{array}{l}\text { Change in Bishop score } \\
\text { (Final - Initial) }\end{array}$ & $3(1-7)$ \\
mean (min. - max.) & \\
Prostaglandins after Foley cervix priming & $107 / 201(53)$ \\
$\begin{array}{l}\text { Total induction-to-delivery time (hours) } \\
\text { mean (min. - max.) }\end{array}$ & $38(4-120)$ \\
Vaginal delivery & $142 / 201(71)$ \\
Vaginal delivery after cesarean & $15 / 40(37)$ \\
\hline
\end{tabular}

In half of cases (108/201) the catheter was removed 24 hours after its insertion. In 46\% (93/201) of inductions, the catheter was spontaneously extruded on average 15 hours (1 - 19) after its introduction.

The mean change in Bishop score after catheter placement was 3 (1 - 7); in 11 cases it remained unchanged after catheter removal (5\%).

The mean variation of VAS Pain after cervical priming with Foley catheter was 1 (range 0 - 8), with only $9 \%$ $(19 / 201)$ patients describing a moderate pain after catheter. The rate of vaginal delivery was $71 \%$ (142/201). Of the 59 cesarean deliveries, 30 were for labor arrest disorders, 12 for suspected fetal hypoxia and 16 for negative induction of labor. Within the sample, 40 women had a previous cesarean section, with a VBAC rate of $37 \%(15 / 40)$.

In 94 cases, after the removal of the Foley catheter, the induction of labor proceed with oxytocin infusion but in the other 107 women cervical priming was continued with the administration of misoprostol. Excluding the 40 women that had had a previous cesarean section, there was no significant statistical difference in the rate of vaginal deliveries between the group that had priming with Foley catheter followed by misoprostol $(84 / 107)$ versus the group with only Foley catheter $(43 / 54)(p=0.87)$.

The mean induction-to-delivery time was 38 hours (4 - 120). Excluding the cases with a previous cesarean section there was a statistically significant difference in the mean induction-to-delivery time between the group that had priming with Foley catheter followed by misoprostol (41 hours) and the group with Foley catheter followed by oxytocin (31 hours) $(p<0.01)$.

The rate of peripartum fever $\geq 38^{\circ} \mathrm{C}$ was $3 \%(6 / 201)$. There was only one case of significant vaginal bleeding with the need to remove the catheter and three cases of tachysystole, only one of them with changes in fetal heart rate. All cases of tachysystole were reported after the administration of prostaglandins. There has been no significative maternal or neonatal morbidity (Table 2).

\section{DISCUSSION/CONCLUSION}

We reported a series of labor induction with previous cervix priming with mechanical methods and described its efficacy in terms of vaginal delivery rate $(71 \%)$ and average induction-to-delivery time (38 hours).

In our sample, Foley catheter priming resulted in a mean variation of Bishop score of 3 which is in accordance with what is described in the literature. Use of catheters has been associated with a mean change in Bishop score of 3.3 to $5.3 .^{8}$

We included all the cases with an unfavorable cervix, which were submitted to a mechanical method as a first choice. After catheter removal or spontaneous extrusion, the induction proceeded in accordance with BS. In cases of favorable cervix, oxytocin was administered and in this group we verified a statistically significant lower average induction-to-delivery interval compared to the group with persistent unfavorable cervix that needed prostaglandins after mechanical priming. This is easily understood since the BS after Foley catheter in the group that proceeded induction with oxytocin was higher than in the group that needed prostaglandins after priming with Foley catheter. A higher Bishop score increases the probability of vaginal delivery in spontaneous or induced labor. . $^{1,8,9}$

Intracervical catheters have been considered painful methods for cervix priming. ${ }^{10}$ Nonetheless, data on maternal satisfaction is lacking. We tried to evaluate maternal satisfaction by an objective record of pain related with the placement of the Foley catheter. We verified that the majority of the cases reported very light or no pain, making Foley catheter a well-tolerated method of cervix priming.

In our cohort sample of women with unfavorable cervix we verified a vaginal delivery rate of $71 \%$ with an average induction-to-delivery time (38 hours). Studies that compared prostaglandins alone and the combination of a balloon catheter with a prostaglandin for cervix priming resulted in fewer failures to vaginal delivery within 24 hours for the combination group (RR $0.45 ; 95 \% \mathrm{Cl} 0.28-0.71 ; 3$ trials, 698 women), but a similar cesarean delivery rate (RR $0.92 ; 95 \% \mathrm{Cl} 0.79-1.08 ; 8$ trials, 1295 women). ${ }^{4}$ There are no randomized controlled trials evaluating the efficacy of a balloon catheter and prostaglandins compared with the use of a catheter alone for cervical priming. This was not the aim of our study. A recent report has demonstrated that cervix priming with Foley catheter was associated with shorter induction to delivery interval and more deliveries within 24 hours, compared with prostaglandins (PGE2) with no difference in the cesarean delivery rate. ${ }^{11}$

Many obstetric societies advise against the use of prostaglandins for cervical ripening or labor induction in women in the third trimester with prior uterine incisions because of the risk of uterine rupture. Nonetheless, ACOG and Society of Obstetricians and Gynaecologists of Canada consider mechanical methods a safe option for trial of labor after cesarean delivery (TOLAC). ${ }^{12,13}$ Our study reinforces the role of mechanical methods for TOLAC since we included 40 women with a previous cesarean section and achieved $37 \%$ of VBAC with no documented maternal or neonatal morbidity.

In our study the rate of peripartum fever $\geq 38^{\circ} \mathrm{C}$ was $3 \%$. Controversy exists about the infectious risk of Foley catheter urging new investigation. ${ }^{10,14} \mathrm{~A}$ recent systematic review has suggested that Foley catheter is not associated 
with an increased risk of infectious morbidity. ${ }^{15}$ Controlled randomized studies should clarify the possibility of using the method in pregnant women colonized with Streptococcus group B with adequate antibiotic prophylaxis in the same terms that are applied to other methods of induction of labor. The only difference in intracervical catheters compared to pharmacological methods is the insertion of a foreign body. Considering that the catheter is sterile and the existence of intact membranes, the theoretic and additional risk of chorioamnionitis should be negligible.

As far as we know this is the first case series of cervix priming with Foley catheter that is presented in Portugal. Nonetheless we acknowledge the fact that we used each case as its own control in order to evaluate efficacy, with no external controls as a limitation of our study.

Future investigation about mechanical methods for cervix priming should also focus on the possibility of outpatient priming of cervix with these methods, contributing to decrease the costs and maternal dissatisfaction resulting from long inpatient periods associated with induction of labor with an unfavorable cervix. Mechanical methods promote cervical modification without increasing uterine contractions, being promising for cervix priming for women

\section{REFERENCES}

1. Roumen FJ, Dehing CJ, van den Akker ES, Aarts MJ, Scheve EJ. Bishop score and risk of cesarean delivery after induction of labor in nulliparous women. Obstet Gynecol. 2005;105:690-7.

2. Jozwiak M, Oude Rengerink K, Benthem M, van Beek E, Dijksterhuis MG, de Graaf IM, et al. PROBAAT Study Group Foley catheter versus vaginal prostaglandin E2 gel for induction of labour at term (PROBAAT trial): an open-label, randomised controlled trial. Lancet. 2011;378:2095103.

3. Shechter-Maor G, Haran G, Sadeh-Mestechkin D, Ganor-Paz Y, Fejgin MD, Biron-Shental T. Intra-vaginal prostaglandin E2 versus doubleballoon catheter for labor induction in term oligohydramnios. J Perinatol. 2015;35:95-8

4. Jozwiak M, Bloemenkamp KW, Kelly AJ, Mol BW, Irion O, Boulvain M. Mechanical methods for induction of labour. Cochrane Database Syst Rev. 2012;14;3:CD001233.

5. Heinemann J, Gillen G, Sanchez-Ramos L, Kaunitz AM. Do mechanical methods of cervical ripening increase infectious morbidity? A systematic review. Am J Obstet Gynecol. 2008;199:177-87.

6. American College of Obstetricians and Gynecologists. ACOG Practice Bulletin No. 116: management of intrapartum fetal heart rate tracings. Obstet Gynecol. 2010;116:1232-40.

7. Spong CY, Berghella V, Wenstrom KD, Mercer BM, Saade GR. Preventing the first cesarean delivery: summary of a joint Eunice Kennedy Shriver National Institute of Child Health and Human Development, Society for Maternal-Fetal Medicine, and American College of Obstetricians and with a previous uterine scar or for outpatient cervical priming without the need of continuous fetal cardiotocography monitoring.

Foley catheter is a safe and effective method for cervix priming in case of unfavorable cervix.

\section{PROTECTION OF HUMANS AND ANIMALS}

The authors declare that the procedures were followed according to the regulations established by the Clinical Research and Ethics Committee and to the Helsinki Declaration of the World Medical Association.

\section{DATA CONFIDENTIALITY}

The authors declare having followed the protocols in use at their working center regarding patient's data publication.

\section{CONFLICTS OF INTEREST}

The authors declare that there are no conflicts of interest.

\section{FUNDING SOURCES}

No subsidies or grants contributed to this work.
Gynecologists Workshop. Obstet Gynecol. 2012;120:1181-93

8. Gelber S, Sciscione A. Mechanical methods of cervical ripening and labor induction. Clin Obstet Gynecol. 2006;49:642-57.

9. Ezebialu IU, Eke AC, Eleje GU, Nwachukwu CE. Methods for assessing pre-induction cervical ripening. Cochrane Database Syst Rev. 2015;6:CD010762.

10. Jonsson M, Hellgren C, Wiberg-Itzel E, Akerud H. Assessment of pain in women randomly allocated to speculum or digital insertion of the Foley catheter for induction of labor. Acta Obstet Gynecol Scand. 2011;90:9971004.

11. Mizrachi Y, Levy M, Bar J, Kovo M. Induction of labor in nulliparous women with unfavorable cervix: a comparison of Foley catheter and vaginal prostaglandin E2. Arch Gynecol Obstet. 2016;294:725-30.

12. American College of Obstetricians and Gynecologists. ACOG Practice bulletin no. 115: vaginal birth after previous cesarean delivery. Obstet Gynecol. 2010;116:450-63.

13. Society of Obstetricians and Gynaecologists of Canada. SOGC clinical practice guidelines. Guidelines for vaginal birth after previous caesarean birth. Number 155. Int J Gynaecol Obstet. 2005;89:319-31.

14. Heinemann J, Gillen G, Sanchez-Ramos L, Kaunitz AM. Do mechanical methods of cervical ripening increase infectious morbidity? A systematic review. Am J Obstet Gynecol. 2008;199:177-87.

15. McMaster K, Sanchez-Ramos L, Kaunitz AM. Evaluation of a transcervical Foley catheter as a source of infection: a systematic review and meta-analysis. Obstet Gynecol. 2015;126:539-51. 